DIGITAL COMMONS
@ UNIVERSITY OF SOUTH FLORIDA

Volume 2

Issue 1 Volume 2.1 (Spring 2012): Open Access

\section{ABO: Interactive Journal for Women in the Arts, 1640-1830}

\title{
Living in a Digital World: Rethinking Peer Review, Collaboration, and Open Access
}

Sheila Cavanagh

Emory University, engstc@emory.edu

Follow this and additional works at: https://digitalcommons.usf.edu/abo

Part of the Dramatic Literature, Criticism and Theory Commons, Educational Methods Commons, Feminist, Gender, and Sexuality Studies Commons, and the Literature in English, British Isles Commons

\section{Recommended Citation}

Cavanagh, Sheila (2012) "Living in a Digital World: Rethinking Peer Review, Collaboration, and Open Access," ABO: Interactive Journal for Women in the Arts, 1640-1830: Vol.2: Iss.1, Article 15. http://dx.doi.org/10.5038/2157-7129.2.1.14

Available at: https://digitalcommons.usf.edu/abo/vol2/iss1/15

This New Media is brought to you for free and open access by Digital Commons @ University of South Florida. It has been accepted for inclusion in ABO: Interactive Journal for Women in the Arts, 1640-1830 by an authorized administrator of Digital Commons @ University of South Florida. For more information, please contact digitalcommons@usf.edu. 


\section{Living in a Digital World: Rethinking Peer Review, Collaboration, and Open Access}

\section{Keywords}

access, collaboration, digital, peer review

Creative Commons License

(c) $($ ) $\odot$

This work is licensed under a Creative Commons Attribution-No Derivative Works 3.0 License. 
It's no secret that times are tough for scholars in the humanities. Jobs are scarce, resources are stretched, and institutions of tertiary education are facing untold challenges. Those of us fortunate enough to hold tenured positions at financially stable colleges and universities may be the last faculty to enjoy such comparative privilege. The future shape of the academy is hard to predict, except to acknowledge that it is unlikely to remain static. Our profession is being rapidly reconfigured, but many changes are not happening quickly enough. In the realm of the digital, for example, entrenched traditional standards of assessment, support, and recognition still fail to encourage the kind of exciting new research that keeps our disciplines vibrant. While some organizations, such as the Modern Language Association (MLA), and the National Endowment for the Humanities (NEH) have made significant efforts to address the need for national dialogues about germane topics, numerous faculty members, department chairs, deans, and others involved in the faculty reward system continue not to understand the shifting parameters of research, teaching, and service that have been instigated by the digital revolution. Many of these individuals, in fact, remain unaware of their ignorance. Those who do not work in digital realms themselves often unwittingly contribute to an environment that impedes intellectual innovation. Despite the pressing need for reconfigured standards of evaluation and new approaches to mentoring, many of those holding the power to address this situation do not recognize the issues at stake. Failure to redress current circumstances would have serious consequences for the humanities. Fields such as those promoted by this journal are especially vulnerable, since they often do not attract the widespread attention needed to survive in difficult times. It is important, therefore, for administrators and faculty at all levels to respond to the particular ways that conventional academic evaluative and mentoring models often inadvertently impede important new work. In a letter to the MLA, past President Sidonie Smith notes: "Experimenting with new media stimulates new habits of mind and enhanced cultures of collegiality. Future faculty members in the modern languages and literatures will require flexible and improvisational habits and collaborative skills to bring their scholarship to fruition” (2). Smith's remarks reflect the evolving reality of today's academy. As we struggle with shrinking resources and other changes to our academic environment, her words demand careful consideration.

As director of the Emory Women Writers Resource Project (EWWRP) since 1995, editor of the Spenser Review (now online rather than produced in print) and co-director, with Dr. Kevin Quarmby, of the World Shakespeare Project (WSP), I have a personal investment in the success of the Digital Humanities (DH). As a tenured, full professor, however, my career is not unduly influenced by the status of my digital work. During previous promotion deliberations, my digital contributions - predominantly focused on the study of early modern women-were ignored. At this point, I enjoy the opportunity to pursue such avenues without worrying about employment security. While my professional reputation and compensation are still influenced by my scholarly productivity, whether digital or in print, such pressures are obviously less critical than those facing graduate students and junior scholars. As collaborator and mentor to several such members of the academic community, I would like to draw from my experience with their projects to illustrate some of the ways that scholarship is changing and to suggest the kinds of concurrent alterations needed in our assessment and mentoring practices. As my title suggests, I believe that our traditional conceptualization of peer review, the humanities' continuing hesitance to support collaborative ventures, and our common inability to mentor junior colleagues appropriately remain primary obstacles to the kind of DH work that can help our 
disciplines flourish even during difficult times. While “open access” in today's academic discourse generally signifies freely available digital materials, I would like to expand that term in order to examine the obstacles impeding junior scholars seeking open access to digital creation.

One of the changes I want to highlight is the way that "peer review" has evolved fairly quietly during the expansion of digital scholarship and pedagogy. Even though some scholars, such as Kathleen Fitzpatrick, are addressing the need for new models of peer review, recognition of the ways that this process has already been transformed in the digital realm remains limited. The 2010 Center for Studies in Higher Education (hereafter cited as Berkeley Report) comments astutely on the conventional role of peer review in the academy:

Among the reasons peer review persists to such a degree in the academy is that, when tied to the venue of a publication, it is an efficient indicator of the quality, relevance, and likely impact of a piece of scholarship. Peer review strongly influences reputation and opportunities. (Harley, et al 21)

These observations, like many of those presented in this document, contain considerable wisdom. Nevertheless, our understanding of peer review could use some reconsideration in light of the distinctive qualities and conditions associated with DH. The status of peer review has shifted, but there have not been sufficient conversations about the implications of those changes. While there is some understanding that digital work demands new configurations of review, there is still insufficient awareness that these processes have already been changed in substantial ways. Nevertheless, some scholars, such as Steve Anderson and Tara McPherson, emphasize the dangers accompanying such shortsightedness:

Yet we resist such change at our peril. In a moment when universities and governments in the United States and abroad seem intent on shrinking the humanities and on interrogating their value, digital media offer an avenue to reinvigorate our scholarship and to communicate it in compelling new ways. This capacity of the digital to present work to a broader audience means that our work can circulate in many forms, in different affective registers, and in richer dialogues. (149)

The work of many scholars would benefit from such changes. As market forces and other nonintellectual considerations reduce opportunities for scholarly exchange in smaller humanistic fields, such as women's writing, electronic media offers great promise that should be supported, rather than constrained.

As an example of important alterations already silently occurring in the peer review process, I would like to draw attention to the work of Dr. Melanie Doherty, a junior humanist at Wesleyan College in Macon, Georgia, a college serving a socioeconomically diverse population of women. A few months ago, Dr. Doherty sent me (as Director of the EWWRP) an email, asking if I would be interested in a digital archive project that she was creating with Sybil McNeil in the Wesleyan Library. Her message offered an overview of this endeavor: 
As Wesleyan College celebrates its 175th anniversary this year as the first college in the world chartered to grant degrees to women, our library has begun to digitally archive student writings and artifacts from the mid-19th through 20th century. Wesleyan holds a wealth of unique materials discussing women's history in the South. These include student writings, speeches from visiting dignitaries, and letters from notable 19th- and 20th-century feminists, as well as photos, clothing and artworks that span the school's rich past from the 1840s to the present day. These artifacts detail invaluable information about the lives of women in the antebellum South through the world wars, women's suffrage, and Civil Rights movements, all documenting the achievements of women with fascinating insight into their daily lives.

Your collection has already featured work from some notable Wesleyan alums, including Loula Kendall Rogers, and we have much more material that would be relevant to the Emory archive. As sister college to Emory, and as your institution also celebrates its 175th anniversary this year, we thought this might present a great opportunity to collaborate.

Intrigued by the project, I met with Dr. Doherty several times in person and over Skype. I also gathered a group of relevant local library and technological personnel, so that we could all discuss whether and how Wesleyan's archival efforts could be supported by Emory. As these conversations evolved, several key issues emerged regarding the atypical nature of peer review and collaboration in $\mathrm{DH}$. The academic review aspect of this undertaking illustrates a noteworthy, but under-recognized shift in the professional trajectories of junior scholars involved in DH. Dr. Doherty approached me, in part, because Wesleyan does not have sufficient server capacity to house any archives that she and McNeil are able to produce. In addition, Emory (and Georgia Tech, another potential partner) possesses a range of technological equipment and expertise that Wesleyan cannot replicate. Facing such obstacles is a standard feature in modern digital scholarship, as the Berkeley Report makes clear:

humanists are seldom able to pay for extensive support out of personal research funds and many voiced the need for "in-house" (i.e., institutional) technical support for individual research projects. Libraries are often on the front lines of supporting these faculty with their research and publication needs. For example, the library is assumed, in many cases, to be the locus of support for archiving, curation, and dissemination of scholarly output. (27)

Accordingly, Doherty proposed that the EWWRP might house the Wesleyan archive as a distinctive collection among the others currently comprising this digital enterprise. This prospect made immediate sense to me. The Wesleyan archive appears to be of significant academic interest, and I believe strongly in supporting the efforts of talented junior scholars, particularly when they are working on projects involving Women's Studies and DH.

Over the years, I have been able to offer tangible, moral, and advocacy support to a number of less-established scholars, both male and female, who have grown interested in these fields. In this instance, however, while I could fulfill the crucial role of facilitator, I could not provide the 
level of authorization that Dr. Doherty would need in order to submit the strong grant proposal she was trying to create. Although I direct the EWWRP, I do not "own" the digital space it inhabits. I work closely with colleagues in Academic Technology and the Woodruff Library, but I make no decisions regarding the allocation of their time, expertise, or priorities. At the same time, these colleagues typically have some ability to determine where to devote their attention, but generally lack the authority to decide independently what kinds of projects they will support in their capacity as Emory employees. As I note elsewhere (Cavanagh 5), this situation contrasts dramatically with my experience of starting the EWWRP. In the mid-nineties (a lifetime ago in digital chronology), faculty and librarians at Emory faced comparatively few similar constraints. It was an era of fledgling digital exploration. Those of us experimenting in these realms formed partnerships with limited official interference. We were not required to justify our efforts very often, in part because relatively few people were paying much attention. Dr. Chuck Spornick and Dr. Alice Hickcox in the Lewis H. Beck Center for Electronic Collections and Services were charged with supporting faculty with digital endeavors. Fortunately for me, they were eager to become engaged with the EWWRP and have remained valuable collaborators ever since.

Today, however, there are a number of competing needs and priorities that potential Emory partners, such as Dr. Hickcox in the Beck Center and Dr. Stewart Varner of Emory’s Digital Scholarly Commons, need to address before they can offer ongoing participation in any project. Like other units of the university, Woodruff Library has its own Strategic Plan detailing its official ambitions, goals, and priorities. Within the Library and in various divisions of Information Technology, numerous business plans and other germane documents identify the kinds of endeavors that will further these aims. As readers of this journal probably know all too well, women writers and women's history are not likely to figure prominently in typical university technological vision statements. There may or may not be active opposition to this kind of academic focus, but faculty in these fields cannot presume that everyone will recognize the value of such projects. The individuals making decisions about technological resources are often not scholars themselves, while even those who offer both scholarly and technical expertise are likely to come from disparate fields. Accordingly, while "review" remains, traditional conceptualizations of "peer” recede.

This common situation leads to the largely unseen shift in the kind of review current digital scholars encounter. In traditional print scholarship, faculty face peer review much later in the trajectory of their research. They might, at some point, apply for a grant, but many humanistic scholars complete their projects successfully with appropriate access to relevant library collections and sufficient time to devote to their research. Faculty at more affluent institutions often "access" more financial resources and more amenable teaching loads than their colleagues with less comfortable circumstances, but everyone is eligible to apply for grants and fellowships from organizations like the NEH or the ACLS. According to conventional wisdom, moreover, scholars are often best situated to receive such grant support if they apply after their work is largely completed. Applications written when the relevant research has already been done are said to provide more compelling accounts indicating the worthiness of the project. I have never seen non-anecdotal evidence confirming this common belief, but the premise carries considerable logical merit. 
Digital work, such as Dr. Doherty's, cannot be created under comparable circumstances, however. As detailed above, the successful implementation of her plans for a digital archive requires a significantly different review process. She cannot present a finished or nearly completed project for evaluation; she needs approval from varied sources before she can even proceed past the conceptual stage of her endeavor. Numerous people from several institutions need to agree that her idea holds merit and fits within existing, non-scholarly priorities, before she can move forward with it. This situation reflects today's norm. As the MLA Guidelines for Evaluating Work with Digital Media in the Modern Languages suggests, digital scholars invariably work with a range of project collaborators:

Humanists are not only adopting new technologies but are also actively collaborating with technical experts in fields such as image processing, document encoding, and information science. Academic work in digital media should be evaluated in the light of these rapidly changing institutional and professional contexts, and departments should recognize that some traditional notions of scholarship, teaching, and service are being redefined.

Notably, however, this now common reconfiguration of faculty work makes it difficult to characterize the procedures Doherty followed as involving traditional "peer review." Unlike the "blind" evaluative procedures followed in conventional promotion, tenure, and grant reviews, Dr. Doherty needed to approach people openly and directly. She also required assistance in determining who to contact at potential partner institutions, since such information can be impossible to discern from university websites. In addition, the typical conceptualization of what constitutes a "peer" becomes complicated in these instances. Since a digital project demands support outside the faculty of a given institution, the work regularly requires authorization from those who do not typically engage in faculty peer review. The necessary evaluation, moreover, often includes serious consideration of factors that have nothing to do with scholarly quality. Like the many university presses that have eliminated monograph series or gone "trade" for financial rather than intellectual reasons, those able to authorize digital projects make decisions based on a broad range of considerations that are distinct from elements key to promotion and tenure discussions. At a large university, for example, projects in the humanities may be competing for funding and attention with proposals from diverse professional schools. Resources might be allocated by individuals without a particular commitment to the humanities or by those holding any number of competing interests. Unlike a journal article, book proposal, or grant application that is sent to an "expert" in a relevant field, a digital decision can be made by people from a range of positions, both academic and not, within a college or university. A successful application may indicate scholarly value, but not necessarily, just as a failed proposal may stop a scholar in his or her tracks, but may not suggest that the idea was flawed. Obviously, traditional scholarship also confronts the influence of chance, mistake, or other arbitrary roadblocks, but the distinctive situation facing scholars in DH is not widely acknowledged. While a scholar applying for a research grant from the Folger Shakespeare Library does not generally face an applicant pool containing faculty from Engineering, Business, or Law, faculty pursuing digital support often do. The concept of “open access," therefore, which many academics currently perceive as a primary value in digital production, exists in an environment that is far less open than many scholars recognize. Successful projects may be disseminated through the process termed "open access," but that does not mean that there is "open access” to developmental resources. In reality, 
"open” access to the range of personnel and equipment needed to bring a DH project to fruition is rarely available.

For the purposes of this essay, I am not proposing a specific, “one size fits all” response to these circumstances; rather, I am encouraging faculty who hire, tenure, and mentor junior scholars to acknowledge the complicated factors in the world of digital scholarship needing attention. In addition to the under-recognized importance of "non-peer review" in digital undertakings, for example, faculty often have difficulty identifying appropriate experts to participate in more traditional peer review processes. Could an Aphra Behn scholar with no background in electronic media, for instance, provide appropriate evaluation of a digital Behn resource? Would a digital humanist with no familiarity with Behn be a more or less qualified assessor? At what stage is peer review needed? As the MLA Guidelines indicate, "Faculty members who work with digital media should have their work evaluated by persons knowledgeable about the use of these media in the candidate's field.” An appropriate level of familiarity with digital work is particularly important for outside reviewers, since many faculty members have not been part of informed discussions about how to evaluate digital scholarship. In a hiring discussion at Emory recently, for example, a normally astute faculty member with little digital background remarked that since anyone can post anything on the web, departments should only evaluate items published electronically after standard peer review processes.

While this perspective is understandable, it demonstrates a common inability to consider the need for revised evaluative guidelines if we are going to encourage innovative new scholarship. "Self-publishing" on the web, for instance, does not correspond to traditional print "selfpublishing” as closely as many non-digitally savvy faculty members believe. The web certainly can serve as an electronic vanity press, but it can also facilitate rapid and revisable dissemination of important scholarly material. Not recognizing the differences between appropriate traditional and digital review is likely to hurt scholarship, as Kathleen Fitzpatrick notes:

Imposing traditional methods of peer review on digital publishing might help a transition to digital publishing in the short term, enabling more traditionallyminded scholars to see electronic and print scholarship as equivalent in value, but it will hobble us in the long term, as we employ outdated methods in a public space that operates under radically different systems of authorization. (9)

As Fitzpatrick suggests, a reimagining of peer review will provide a crucial step toward needed academic progress. Traditional peer review often does not meet the needs of electronic production. In an article on a related topic (Cavanagh 10) I recently described the significant scholarly achievement demonstrated by my colleague Harry Rusche’s “Shakespeare's World” websites, even though Professor Rusche's work did not undergo standard peer review. Since Professor Rusche began his impressive archive long after he received tenure, he was not impeded by the paucity of evaluative bodies available to offer peer review for projects such as his that are created without grant funding. Only a few groups, such as NINES (Networked Infrastructure for Nineteenth-Century Electronic Scholarship) and its "sister” group 18thConnect, provide this type of external review for digital work within their subject areas. In addition, NINES is partnering with the NEH to formulate detailed review guidelines for projects emerging across the $\mathrm{DH}$ horizon (Wheeles). Nevertheless, the "field" of evaluation for digital scholarship is still largely 
under development. In the meantime, both junior and senior faculty members continue to expand their digital projects. While Rusche-a full professor-can devote considerable attention to his acclaimed collection of Shakespearean postcards, however, an untenured scholar would be taking a significant risk by following this example. Although the quality of such work can be assessed through appropriate criteria, many institutions have not addressed what standards might be applicable for their hiring or promotion and tenure processes. "Access" to the opportunity of creating digital work is currently denied to many untenured scholars, therefore. Written guidelines for digital assessment rarely exist and many tenured faculty members remain unable, unwilling, or blind to the need to adapt current promotion criteria to digital scholarship.

Not surprisingly, the "privilege" of undertaking digital scholarship thus often falls to those who have already received tenure through traditional channels. Mentoring practices tend to reinforce this pattern. According to the Berkeley Report, for example:

The advice given to pre-tenure scholars was quite consistent across all fields: focus on publishing in the right venues and avoid spending too much time on public engagement, committee work, writing op-ed pieces, developing websites, blogging, and other non-traditional forms of electronic dissemination . . . (10)

Scholars on the tenure track accordingly often resist such risky avenues, given the considerable pressures associated with the pre-tenure probationary period. Academics with even less employment stability, such as graduate students and other non-tenure track scholars, face additional challenges that also need more serious attention than they currently receive. In the next section of this discussion, I would like to highlight the work of three such scholars, graduate students Amy Elkins and Catherine Doubler at Emory, and my collaborator, Dr. Kevin Quarmby, a recent Ph.D. who teaches in London. None of these promising scholars currently hold tenure track positions. They are all involved in exciting digital projects, however, that demonstrate the short-sightedness of pushing scholars to postpone such endeavors until after tenure, while underscoring the significant scholarly benefits possible if faculty and administrators more actively encouraged electronic scholarship of many kinds.

Amy Elkins won the 2011 South Atlantic Modern Language Association Graduate Student Essay Prize for her essay, "Cross-Cultural Kodak: Snapshot Aesthetics in the Fiction of Virginia Woolf.” This print essay is forthcoming in South Atlantic Review. As this accolade suggests, Ms. Elkins is a talented literary scholar, whose graduate career shows great potential. Fortunately, she is not restricting herself to the print domain, however. One of her scholarly projects involves the creation of an intriguing digital archive that draws from several institutional collections. She describes the project in a recent email:

For some time I've been working on creating a digital archive of the Potter's Wheel, a manuscript magazine created by Sara Teasdale and a group of women artists and writers (they called themselves The Potters) in St. Louis from 19041907. I've located all of the extant manuscripts in special collections libraries, and I've been working to get those libraries to digitize their holdings so that I can get the page images on an Omeka site. I envision a scholarly resource, as well as a teaching resource for a range of scholars across the disciplines. 
Elkins details the trajectory of her digital creation in terms that resonate with many who enter this field:

Working on a DH project has put me in touch with a whole range of amazing scholars. I've opened up lines of communication with professors who have an interest in DH such as yourself, a wonderful Teasdale scholar who is totally behind the archive, other graduate students working on the intersection of visual art, book history, and the digital, and a network of DH enthusiasts on Twitter. . . Also, the staff at Yale's Beinecke Library has been tremendously helpful. . . The hindrances: Not all libraries are equipped to do high quality digitization or they don't want to use their manpower helping someone from another institution. DH is truly collaborative, which means that you have to rely on other people to get the balls rolling.

As Elkins is discovering, the collaborative efforts involved in digital work can be both exhilarating and frustrating. They also require a different skill set than was needed by many of the tenured faculty who are mentoring upcoming generations of students. Traditional print scholarship often leads to intellectual exchanges at conferences and elsewhere, but it does not demand cooperation as frequently as $\mathrm{DH}$ does. While there may be a range of personality types represented among humanities academics, the conventional image of a scholar working in comparative isolation corresponds to the largely solitary process that has led to many scholarly articles and monographs in print. One might eagerly share ideas with colleagues over coffee at the Newberry Library, for instance, but the rest of an archival scholar's day is likely to be spent predominantly with the library's holdings. Conversations with knowledgeable colleagues may be valuable in this model, but they are generally not imperative for the mere existence of a project. In DH, however, it is a rare scholar who is able to actualize an entire project without substantial contributions by a host of technologists, librarians, and others whose knowledge complements that provided by the scholar(s) envisioning an electronic product.

These necessary partnerships offer further complications to issues involving access. Clearly, collaborative work has a different history in the humanities than in the sciences and conventional reward structures in humanistic disciplines do not always easily accommodate mutual efforts. Although a few humanists, such as Lisa Ede and Andrea Lunsford, address the challenges and benefits of collaborative work, humanistic fields have generally not caught up with such work. Procedures for determining how to assess individual contributions to joint endeavors can be developed, but most humanities departments have yet to initiate such discussions in any serious or systematic way. Given the widely recognized transformation within traditional print publication outlets, humanities scholars cannot afford to postpone such vital discussions any longer. Newer scholars need to produce work within current practical restraints. Senior faculty who assess this scholarship and who hire and mentor this cohort are irresponsible if they do not acquire the knowledge they need in order to bring promotion and tenure criteria into alignment with technological, material, and philosophical changes in the intellectual marketplace. Standards do not need to be lowered, just shifted. Senior faculty must recognize, for instance, that many common contemporary scholarly practices, such as collaboration, can no longer be 
perceived as aberrant or unworthy of “credit.” In addition, as the MLA guidelines for evaluating electronic scholarship suggests, "credit” may need to be allocated unconventionally:

Institutions should also take care to grant appropriate credit to faculty members for technology projects in teaching, research, and service, while recognizing that because many projects cross the boundaries between these traditional areas, faculty members should receive proportionate credit in more than one relevant area for their intellectual work. (“Guidelines”)

Digital scholarship is transforming our professional lives and none of us will benefit by ignoring or resisting the challenges introduced by these new formats and modes of thinking. Noting the importance of such academic reconfigurations, the Berkeley Report suggests that: "As faculty continue to innovate and pursue new avenues in their research, both the technical and human infrastructure will have to evolve with the ever-shifting needs of scholars” (iii). Concurrently, the professoriate will also need to expand the range of topics and media that are welcomed into scholarly conversations. As a graduate student in the 1980's, I was warned not to undertake scholarship on women writers until I had tenure. Similar cautions were offered to many contemporaries with scholarly interests in other fields deemed professionally "risky." Over the years, the kinds of scholarship prompting such suspicion may change, but a pattern of resistance to certain topics of inquiry recurs. As digital options broaden the types of presentation models available to scholars, multimedia presentations also arouse both caution and suspicion. Senior "gatekeepers" thereby stand in the way of vibrant modes of innovation that may keep the humanities alive.

Catherine Doubler's work demonstrates how limiting such intellectual restrictions can be. Her self-designated "second book project" concerns the work of the controversial "anti-Stratfordian" Delia Bacon. Understandably viewed skeptically by the Shakespearean establishment, long wearied of spurious claims against the "Bard of Avon," Bacon is the kind of figure junior scholars are traditionally being warned against investigating. Doubler, however, is expanding her expertise in Bacon's fascinating intellectual legacy with its surprising connections to today's digital world, while she completes her dissertation on Renaissance drama and becomes adept with electronic media. As a result, Doubler is creating a tangible scholarly product while exploring intriguing questions about the relationship between theoretical issues emerging through modern media and those raised by earlier intellectuals such as Bacon. At the moment, Doubler is working on digital editions of Bacon's three novellas, The Tales of the Puritans. As she describes this undertaking, Doubler highlights the unexpected theoretical issues emerging through this digitization effort: “I thought that representing Bacon’s life and work in digital venues could fittingly highlight her own interest in literature and technology.” As part of this electronic process, Doubler has been learning TEI (Text Encoding Initiative) mark-up, which she finds intersects significantly with Bacon's work:

I have had to make use of two systems of codes when looking at The Tales of the Puritans: the first concerns itself specifically with literary meaning while the second takes a less logocentric view in order to make the novel legible in an online format. As such, I would like to use my experiences of putting Bacon into code to reflect on 
Bacon's own obsessions over the concepts of ciphers and secret Languages.

While Doubler's investigation of Bacon's life and works and her translation of these novellas into digital format are still in embryonic form, the questions emerging make it clear that the theories and practices accompanying modern technology can illuminate such earlier texts in fruitful ways. Whether or not Delia Bacon proves to be a more promising figure of study than previous Shakespeareans have thought, the connection between nineteenth- and twenty-firstcentury technological codes opens exciting new realms of study. Working digitally in this way can make such work available, bypassing non-qualitative concerns that often stall print publication. This kind of intellectual risk-taking leads to lively and productive humanistic research. In contrast, keeping certain modes and topics “off limits” to junior scholars impedes critical progress, just as demanding scholarly isolation inhibits exploration of the intriguing questions new technologies foster. Broadening the concept of "open access," on the other hand, to make a wider range of scholarly topics and practices "open," can invigorate the humanities during these times of debilitating constraints. Expanding the communal impulse behind the now commonly conceived understanding of open access could transform humanistic research.

The kind of energizing intellectual and practical collaboration that Amy Elkins has encountered in her Teasdale work and Melanie Doherty developed for her Wesleyan proposal, moreover, illustrates the importance of expanding and endorsing inter-institutional ventures as well as intellectual partnership between individuals. Emory's strong support of my collaboration with Dr. Kevin Quarmby in London models the brand of forward thinking that can facilitate an array of future scholarly initiatives, but it also demonstrates the value of shared innovation and the benefit of deliberate cooperation between diverse practical and intellectual goals. As our World Shakespeare Project and related endeavors have evolved, we have received practical support from many faculty, staff, and administrators working far outside the realm of early modern drama. Their engagement remains vital to our success, which is largely created through our distinctive, though complementary skill sets. Dr. Quarmby acted professionally in London's West End for many years before completing his Ph.D. at King's College, London in 2008. He currently teaches for a number of academic programs in London, and is actively seeking a permanent, full-time, institutional affiliation. Although still living and working in the United Kingdom, he has been named Distinguished Visiting Scholar at Emory's Halle Institute for Global Learning and Shakespeare Performance Specialist in Virtual Residence at Emory's Center for Interactive Teaching. He has also received support from Emory's Center for Faculty Development and Excellence. Clearly, numerous individuals at Emory see advantages to the university's educational mission through the implementation of this transAtlantic research and pedagogic partnership.

The many Emory educational and technological leaders who are contributing to the work that Dr. Quarmby and I are jointly involved in are not demonstrating blind altruism, however. They are not offering technical support and other assistance simply from generosity. Rather, they see our projects as mechanisms for testing new technological and international opportunities that will benefit the University. They also recognize the value to Emory of Dr. Quarmby's wide-ranging skills as an academic and theatrical practitioner. Our first electronic collaboration, which is ongoing, involves Dr. Quarmby leading acting workshops with students enrolled in an upper- 
division Shakespeare class. Uniformly praised by undergraduate participants, these sessions enable us to explore the technological and pedagogical opportunities of co-teaching simultaneously from two different countries while offering students the unique perspective provided by a Shakespearean scholar, who has also performed professionally at some of Britain's most renowned venues, such as the Old Vic and the National Theatre. Alan Cattier, Director of Academic Technology Services at Emory and an impressive team at Emory's Center for Interactive Teaching, including Wayne Morse, Chris Fearrington, and a cadre of dedicated graduate students, recognize this electronic teaching project as a way to experiment with videoconferencing in a setting where the students are clearly well served. Rather than simply bringing in a guest lecturer for a single class, this technological alliance makes it possible for Dr. Quarmby to work individually with students and to partner with me in planning and assessing assignments. We endeavor to create a sustainable and "scalable" model of electronic collaboration that takes advantage of technological advances responsibly. Emory's continuing dedication to this project helps us accomplish those goals.

The World Shakespeare Project (WSP) has related, but not identical aims. In addition to the technological partners mentioned above, the WSP benefits from the enthusiastic support of Vice Provost Holli Semetko, Director of the Halle Institute for Global Learning and of Professor Steve Walton and his students in the Goizueta Business School. The WSP links electronically with international Shakespearean faculty and students in order to create and sustain Shakespearean education and dialogue opportunities with populations that would not be able to participate in such projects prior to modern technology. Once again, Emory's significant assistance results from the innovative vision of leaders such as Dr. Semetko and Dr. Walton, whose own areas of professional expertise do not include Shakespeare. Nevertheless, they appreciate the broader pedagogical and technological implications of projects such as ours. Dr. Walton's students, for example, are gaining relevant business experience by helping us craft a business plan, while faculty across the campus benefit from our success with communicating internationally despite disparities between time zones, cultural and educational differences, and widely variant technological infrastructures. Dr. Quarmby and myself have a host of intellectual and pedagogical goals to pursue through the WSP, but we can simultaneously fulfill broader institutional needs without compromising our own plans. This kind of mutual benefit does not occur spontaneously, but can result from open discussions and alertness to the needs of our domestic and international partners.

While Shakespearean drama falls outside the central academic scope of this journal, the WSP draws attention to a number of issues pertinent to the intertwined topics of peer review, collaboration, and access that affect scholars in all fields. As a long-time faculty member at a major research university, I am fortunate enough to have an academic base willing and able to support my own work and that of talented colleagues, such as Melanie Doherty and Kevin Quarmby. As noted, Wesleyan College does not possess the computer resources needed to create and maintain its own digital archive, while Dr. Quarmby does not currently have direct access in London to the range of technological expertise available through Emory. While both of these scholars are pursuing worthy academic projects, their institutional affiliations do not provide the resources they need in order to complete their work. Collaboration with a university like Emory is critical, therefore, since this electronic work could not exist otherwise. With the library and archival resources openly available in London, Dr. Quarmby could produce his recent book, The 
Disguised Ruler in Shakespeare and His Contemporaries (Ashgate, 2012), without this kind of institutional backing. Serious digital work, in contrast, remains significantly less possible for scholars working outside robust research institutions. Such projects can be of substantial benefit to individual scholars and to collaborating institutions, however, suggesting that there would be great merit in wider support of such cooperative efforts.

Such inter-institutional cooperation and other collaborative models can lead to projects that benefit all participants. Concurrently, however, they highlight important changes in the shape of faculty work that require more widespread attention. Senior humanists need to recognize, for example, the vital role of evaluation outside traditional "peer review" in the creation and sustenance of the kinds of the digital products discussed here, if they are going to mentor their graduate students and junior colleagues appropriately. In each instance outlined above, most of the key personnel who determined whether or not these projects could continue were not faculty experts in the relevant field. Although some of these individuals hold doctorates, they do not generally fit the disciplinary profile typical departments would use when choosing outside evaluators for these junior scholars' tenure reviews. Instead, they have been trained in a range of subjects, often widely variant from the content specialty of the graduate students and junior scholars approaching them for assistance. While peer review remains important in the academy, senior faculty would do well to mentor junior colleagues about the importance of developing connections outside traditional disciplinary and faculty/staff boundaries. Institutions could profitably offer training to graduate students in the emerging entrepreneurial aspects of their professional lives. Knowing who to contact in an institution for what kind of support is a skill that not all humanists understand instinctively. Many current senior faculty never needed to develop this ability during their own careers. Increasingly, however, access to vital scholarly resources is likely to depend upon developing expanded sets of skills, including many that are not specifically intellectual. The partnership that Dr. Quarmby and I are forging with the Goizueta Business School, for example, and the many links we have created with international institutions, do not result from anything we learned in graduate school, but still illustrate the range of practical skills that are becoming necessary for humanists to create successful careers in their disciplines. While content knowledge will undoubtedly remain central, it is unlikely to be sufficient for a scholar to thrive in a digital environment.

My goal in this essay is to encourage conversations about significant aspects of digital scholarship and pedagogy that have not yet surfaced in the awareness of many key players in the intertwined processes of mentoring, hiring, tenure, and promotion. Those who do not work in electronic realms themselves need to acquire a clearer understanding of the particular requirements of this rapidly expanding scholarly domain. "Access" to the ability to create substantive digital work emanates from markedly different sources than comparable access to traditional scholarship and pedagogy. Once completed, the resulting projects often do not easily fit conventional evaluative mechanisms. Electronic media have become pervasive in all of our lives, just as many institutions are facing severe financial constraints. These concurrent realities bring an urgency to the issues addressed here that contrast with the slow pace that often characterizes significant change in higher education. 
Works Cited

Anderson, Steve, and Tara McPherson. "Engaging Digital Scholarship: Thoughts on Evaluating Multimedia Scholarship.” Profession 2011: 136-51. Modern Language Association. Web. 23 Feb. 2012. http://dx.doi.org/10.1632/prof.2011.2011.1.136

Cavanagh, Sheila T. Emory Women Writers Resource Project. Emory University. 2006. Web. 23 Feb. 2012. http://womenwriters.library.emory.edu/.

---. "How Does Your Archive Grow?: Academic Politics and Economics in the Digital Age.” Appositions: Studies in Renaissance/Early Modern Literature and Culture. 4 (2011). Web. 23 Feb. 2012.

Cavanagh, Sheila T., and Kevin A. Quarmby. . World Shakespeare Project: A Model for Live Shakespeare Interaction in the New Media World. N.p. n.d. Web. 23 Feb. 2012. http://www.worldshakespeareproject.org.

Doherty, Melanie. Message to the Author., 9Aug. 2011. E-mail.

Doubler, Catherine. Message to the Author.24 Oct., 2011. E-mail.

Elkins, Amy. Message to the Author.19 Oct. 2011.

Fitzpatrick, Kathleen. Planned Obsolescence: Publishing, Technology, and the Future of the Academy. New York: NYU P, 2011.Web. 23 Feb. 2012. http://mediacommons.futureofthebook.org/mcpress/plannedobsolescence/.

"Guidelines for Evaluating Work with Digital Media in the Modern Languages.” Modern Language Association. 2012. Web. 23 Feb. 2012. http://www.mla.org/guidelines_evaluation_digital.

Harley, Diane, et al. Final Report: Assessing the Future Landscape of Scholarly Communication: An Exploration of Faculty Values and Needs in Seven Disciplines.CSHE 1.10 (Jan. 2010). Web. 23 Feb. 2012.

Rusche, Harry. Shakespeare Illustrated. Emory College English Department. n.d. Web. 23 Feb. 2012. http://shakespeare.emory.edu/illustrated_index.cfm.

Smith, Sidonie. "Beyond the Dissertation Monograph.” Modern Language Association Newsletter. 42.1 (Spring 2010): 2-3. Web. 23 Feb. 2012. http://www.mla.org/nl_archive.

Wheeles, Dana. "NEH Summer Institute: Evaluating Digital Scholarship.” NINES: NineteenthCentury Scholarship Online. 19 Oct. 2010. Web. 23 Feb. 2012. http://www.nines.org/news/?m=201010. 